ninth day onwards ova appear in the urine, which, oring to the action of the antimony tartrate, have become granular and black. By the end of a fortnight's treatment about half the ova discharged are obviously dead; many are quite opaque.

On about the twentieth day of treatment all the ora coming away will be dead; none will now hatch out on diluting and warming the urine, and if the adult worms are killed, as is probable, live ova will not reappear in the urine. The injections commenced early to affect the ova. The first action of the antimony in ivivo is observed by testing the physiological function of hatching; as more injections are given the ova are increasingly affected and fewer living ova are found; lastly, the parent worms are killed and living ova no longer appear in any circumstances but reinfection. I think it is impossible to maintain that this sterilization change in the ova is not the direct result of the antimony injections. Other drugs also kill the ova, but no drug deals with bilharziasis so completely as antimony tartrate, because none have so great parasitotropic action and so little organotropic in comparison.*

These are changes which must be observed in vivo with the parasites in their natural media; they cannot be adequately studied in the test tube, nor can test-tube observations, however accurate and in many respects valuable, take the place of clinical experience. In support of this, if support be needed, we might contrast Dale and Dobell's ${ }^{4}$ experience with Entamoeba histolytica and emetine in vitro with the clinical results obtained with the same drug.

H. B. Day ${ }^{5}$ investigated a series of 1,000 cases at the Kasr el Aini Hospital, Cairo, and published carefully drawn charts to show the effect of antimony on the ova. He found that the ova of bilharzia in viro are very susceptible to antimony; a short course of four injections will kill them, the effect being seen after about nine days, and it is the same when the doses are continued; it is evident that it is the small dose acting over a prolonged period which kills when antimony is given in clinical practice. When only small doses are given for two or three days dead ora appear after the ninth day, and the effect reaches its maximum on the fifteenth day, after which living ova become more and more numerous Thus a rery little antimony given kills the ova, but the worms revive and recommence laying. We have actual proof that antimony in a short course does not kill the worms till later, since Day found living worms at a post-mortem examination of a patient who died of an intercurrent disease after a short course.

It has been said by way of objection that granular ora occur in bilharzia cases not undergoing treatment. This is tr ue, but the sudden diminution in the number of living ora coming through after a few days of antimony administration, and the cessation of pain and blood, and the clearing of the urine can only be explained satisfactorily by supposing that antimony has already attacked the ora and paralysed them, or that the worm is under the influence of the drug and therefore is not laying. The ora no longer penetrating the mucous membranes of the bladder. in such numbers there is less cause for haemorrhage, and the urine becomes more acid and natural in appearance.

Further, if the dead ova in a case undergoing treatment are counted and the number compared with the number of live ova, it will be found to be out of proportion to the number of dead ova coming through in a case not receiving treatment. This points to the fact that it is the ova which are killed by the antimony. These shrivelled ova whose double contour is replaced by a single outline, the miracidia within replaced by a shapeless granular mass, always opaque, generally appearing black by transmitted light, are not capable of hatching in any circumstances. The foregoing facts may be verified by anyone with a patient and a microscope.

* One could understand a parasite laying one dead egg or two, which would correspond to abortion in a human being, but is it a biological In other words, is not the action of the tartar emetic a direct one on the ora as they lie in the tissues?
Both Day and I, howerer, obtained in addition results with watery solutions of tartar emetic which showed that there was a distinct, though retarded, action by the antimony on the ora in vitro. In order to imitate natural conditions more closely the former also experimented with saline solutions. Day pointed out that work in vitro has its limitations. A time limit is imposed, since the ova are not in natural surroundings; ther are, in fact, in contact with infected liquids, the ora being recovered from urine which is more or less contaminated with bacteria, whilst when living in the tissues they are bathed in serum-a benign medium from which the orum derives its nutrition. By using serum for the medium the results of experiments on the ova in vitro might possibly have been still more striking.*

I submit, therefore, that in vitro experiments also prove the direct toxic effect of antimony on the ova. They further suggest that the phenomenon of hatching of the bilharzia ova is a vital process, not governed exclusively by physical laws, for whereas antimony appears to have a profound effect on the live ovum, it apparently has no effect on the dead orum.

The action of antimony on the living ova is real, an early manifestation, and only second in importance to the action of the antimony on the adult worms, which it kills later. The action on the ora and on the adult parasite makes antimony the most valuable therapeutic agent we have in bilharziasis, and probably one of the most complete remedies in our therapeutic armoury. ${ }^{10}$

1 Christopherson, J. B. : BRITISH MEDICAL JourAal, December 14th, 1918. 2 Christopherson and Newlove: Journ. of Trop. Med. and Hyg., July 15th, 1919 .

Christopherson, J. B. : Tbid., July 1st, 1920

Dale and Dobell: Journ. of Pharmacol. and Exper. Therapeutics, vol. 10, August 3rd, 1917, 399.

- Day, W. H. : Communication in British Medicli Joursal, March 20th, 1926.

Tairley, N. Hamilton: Trans. Roy. Soc. Trop. Med. and Hygiene, 1926 - Faust, E., Caroll, and Meleny, H. E. : Amer. Journ. of Hygiene, March,

Khalli,

Trans. Roy. Soc. Med., vol. 15, pt. 3, 1921.

Lasbray and Coleman: British MEdic.iL Journal, May, 1924

\section{THE OSCILLOMETRIC EXAMINATION OF ARTERIAL PERMEABILITY.}

BY

\section{A. P. CAWAdias, O.B.E., M.D.Durh. axd Paris,} M.R.C.P.

FORMERLY CHIEF OF MEDICAL CLINIC, BEAUJON HOSPITAL, PARIS, AND SENIOR PHY SICIAN AND LECTURER ON CLINITAL MEDICINE, EVANGELISMOS HOSPITAL, ATHENS.

Ir is often necessary in clinical work to determine the state of permeability of the arteries of the upper or lower limbs. In obliterating arteritis the need for determining the presence of an obliteration, its degree, its localization, and also the condition of the collateral circulation, is frequently felt. In arterial or arterio-venous aneurysms it is necessary to know if the limb is receiving a normal blood supply. In diabetes, in arterio-sclerosis, and in other morbid conditions the degree of permeability of the arteries of the limbs-especially of the lower limbs-is important from the points of riew of diagnosis and prognosis. There are not many clinical methods which assist in answering these clinical problems. Digital examination of the radial or the femoral artery or the dorsalis pedis does not give very definite results. The Moschcowitz and Matas tests, which utilize the degree of the hyperaemic blush following artificial ischaemia caused by the application of an elastic bandage, also fail to give very definite results, and are not without danger in their application.

In 1912 I introduced the oscillometric method for the study of arterial permeability. ${ }^{1}$ It is based on the use of Pachon's oscillometer, and has been developed in France by a great number of workers-principally by Heitz, ${ }^{2}$

* Tartar emetic was shown recently by Fairley ${ }^{7}$ to be relatively innocuous to bilharzia cercaria in aqueous solutions, but it developed marked lethal properties in the presence of human serums derived from both normal and bilharzia patients 
Guyot and Jeanneney,' Pagniez," Gosset, Rénon, and others. An excellent review of this method has been given by Gallavardins in his standard work on the arterial pressure, and by Pachon' in a paper on the oscillometry. If the work of Matas $^{7}$ be excepted, this method of examination is not used extensively in English-speaking countries. Buerger, in his review of the circulatory disturbances of the extremities, does not appear to have followed the literature on this subject, although for the diagnosis of the syndrome of arterial obturation and of thrombo-angiitis obliterans the oscillometric method is, in my opinion, very valuable.

The Method.

Pachon's oscillometer shows the oscillations of the arterial wall under progressive pressure with great accuracy. Eig. 1 shows the oscillations obtained after the armlet has been inflated until no oscillations are shown on the dial of the oscillometer. If the air is allowed to escape very gradually by the valve of the apparatus, and the index of the dial which indicates the oscillations is watched, at first a series of small and equal oscillations, which are called the supramaximal oscillations, are detected. Then comes an oscillation distinctly differing in its extent-the "differentiated oscillation." The oscillations continue to increase progressively and then diminish, and there may therefore be detected the maximum oscillation (MA) and immediately after this maximum oscillation the first descending oscillation (DF). By allowing the air to escape gradually small oscillations are reached once more, and the terminal oscillation (TE) may be determined.

Pachon, his pupils, and various other clinicians use the oscillometric method for the determination of blood pressure. The differentiated oscillation corresponds for Pachon to the systolic pressure, and the degree of this pressure is shown by reading the manometer of the apparatus. The first descending oscillation (DF) indicates the diastolic pressure.

For the application of the oscillometric method to the study of arterial permeability the two oscillations-DI and DF--necessary for the determination of the blood pressure need not be considered, but the three other oscillationsthe initial oscillation, IN, the maximum oscillation, MA, and the terminal oscillation, TE-must be determined. More precisely we must try to determine: (1) the degree of pressure under which the initial (IN) and terminal oscillations appear; (2) the extent-in divisions of the dial of the oscillometer-of the maximum oscillation. This last determination, Pachon's oscillometric index, is the most important. This point should be thoroughly understood, and there must be no confusion between the application of the oscillometer for the determination of the blood pressure in general and its application for tho determination of arterial permeability.

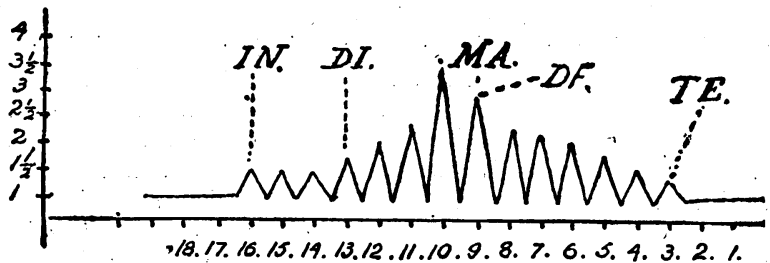

-FiG. 1.-Diagrammatic clinieal oscillometric curve, showing the oscillations as obtained in progressive decompression of the armlet of the oscillometer. The horizontal line indicates the pressure as read in the manometer. (For the corresponding English divisions a zero- must be added. Example: 18 is $180 \mathrm{~nm}$. of mercury, the indion oscillation. DI=Differentiated oscillation. MA=Maximum oscilla. tion. $\mathrm{DF}=$ First descending oscillation. $\mathrm{TE}=$ Terminal oscillation.

If the whole oscillometric curve be determined, or, more simply, if the numbers of the manometer corresponding to the three oscillations under consideration-the initial, the maximum, and the terminal-be noted, it will be found that under normal conditions in the upper limbs the initial is at about 15 or 16 (150 to $160 \mathrm{~mm}$., using the mode of notation customary in England), the maximum extends to 2 or 3 degrees of the dial, and the terminal is found at about 6 or 7. The simple mode of notation $15-3^{\circ}-7$ is here adopted. In the lower limbs the initial is found at about 18, the maximum oscillation extends to 3 or 4 degrees, arfd the terminal oscillation is also found at about 7 or 6 . Adopting the simple notation this may be stated for the lower limbs as $18-4^{\circ}-6$.

This is, of course, schematic because there are many individual variations, and in order to appreciato the differences in the oscillometric curves indicating arterial permeability, it is best to compare the oscillometric curves obtained in different arterial segments by applying the armlet of the oscillometer in various positions on the upper and lower limbs. A special "armlet" has been constructed by Boulitte for the thigh.

In cases of diminished arterial permeability of an artery of the limbs what may be called the oscillometric curve

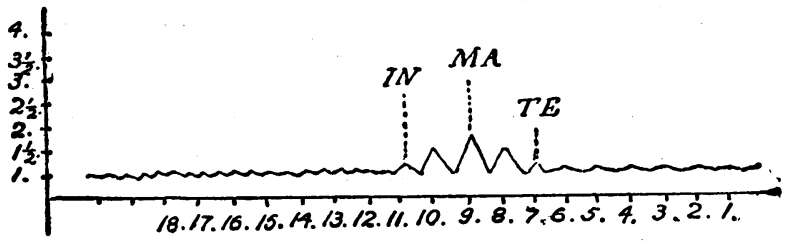

Frg. 2.-Oscillometric curre of arterial obstruction. IN=Initial

of arterial obstruction is found (Fig. 2), in which the initial oscillation appears at a lower pressure (say 7), the amplitude of the maximum oscillation is diminished (for example, to half a degree of the dial), and the terminal oscillation appears at a higher pressure than normally (say 6). This curve indicates that the oscillations of the arterial wall appear later, finish earlier, and are of less amplitude than normally. In other words, as Gallavardin puts it, the " pulsatility" of the artery is diminished.

\section{Clinical Application.}

1. The oscillometric examination of arterial permeability helps in determining whether obliteration exists, and thus in diagnosing whether a syndrome of intermittent claudication is due to an arterial obliteration or to a nervous cause (medullary intermittent claudication, a syndrome of the initial period of Erb's spastic paraplegia).

$\mathbf{K}$. shows a definite symptom-complex of intermittent claudication. Oscillometric examination of the arterial permeability in the two lower limbs 12-1-6; in the two upper limbs 15-4-10. This patient had syphilis and certain difficulty on walking. The patient had syphilis and certain difficulty on walking. Tho onset of a nervous spasmodic syphilitic paraplegia was suspected, but the oscillometric method allowed the diagnosis of the arterial confirmed at post-mortem examination, which showed the presence of big plaques of atheroma of the two external iliac arteries, almost completely obturating these vessels.

Sumbers in the lower limbs and S., a diabetic, complains or numbness in the lower limbs and certain difficulty the wambers for the left lower limb and less low for the right lower low numbers for the left lower limb and less low for the riagnese dislimb. This enabled the diagnosis of arterial origin of these disturbances to be made, a diagnosis which was confirmed by the

When the collateral circulation is good, even aithough a main artery is obliterated, the oscillometric resuits are not abnormal findings. A negative result must not be considered, therefore, as absolute.

2. The oscillometric method allows the course of the disease and the effect of treatment to be followed.

K., aged 30, seen in Paris in 1910. Oscillometric mensurations : lower right limb $14-2-6$, lower left limb $7-1 / 2-4$; upper limbs lower right limb $14-2-6$, lower left two years later. He felt considerably better. Oscillometric mensurations of lower-limbs: right $15-2-9$, left $9-1 / 2-5$. This satisfactory condition did not persist long, and after two years the readings for the upper limbs were 14-3-9; lower right $14-2-9$, lower left $6-1 / 2-5$. One year after no oscillation was detected in the left lower limb.

3. The oscillometric method enables a diagnosis to be made between arterial obliteration due to spasm and that due to definite organic obstacles. As Heitz has shown, when it is caused by spasm a hot local bath brings back normal oscillometric readings.

4. Oscillometric exploration allows the localization of the obliteration to bo determined; the obturations curre being found precisely at the region of the obturation and under that region.

5. Oscillometric estimations have been applied to the examination of the arterial circulation in cases of arterial 
and arterio-venous aneurysm by the author, as well as by Gosset, by Matas, and by Rénon.

M., Colonel in the Greek army, wounded at Kilkis, and showing an arterio-venous aneurysm in the right axilla. Oscillometric examination of the forearm : left $14-2-10$, right $10-1-7$. Two weeks after operation by Professor Gasset the initial oscillation was-12. Ten months after it was $13-2-8$. The radial pulse could not be felt; oscillations were therefore due to collateral could not

This method also shows if a collateral circulation persists in a limb after extirpation of an arterial aneurysm. This is done by taking the oscillometric readings before and after compression of the artery under the aneurysm. If the oscillometric readings are good after compression, extirpation can be applied without danger.

6. Lastly, oscillometric examination will demonstrate the obliteration of a radial artery by an aortic aneurysm or by a tumour of the mediastinum. The involved artery will show the oscillometric curre of arterial obstruction.

\section{Summary.}

Pachon's oscillometer is a very simple clinical instrument and easy to apply. With a little practice anyone can determine the state of the permeability of the tibial artery, of the femoral artery, of the artery of the forearm, and of the brachial artery, and thus study an important element of the peripheral arterial circulation of the patient.

ReFERENCES.

1 A. P. Cawadias: Bull. Soc. Biol. December 7th, 1912; Arch. des Mal. du Cour 1916, p. 201 2 Heit Paris Mléd, Apr, Arch. des Progrès Méd., No. 7, February 13th, 1926; Bull. et Mém. Soc. Miéd. 1913 Hôp. de Paris, April 14th, 1916. '3 Guyot and Jeanneney Journ. de tions of Oscillometry. Paris, 1919. Journ Méd. Fransais Sal Applica1919. "Pagniez: Bull. et Mém. Soc. Méd. des Hôp. de Paris, May 1st 1914. 5 Gallavardin: Arterial Pressure in Clinical Medicine secon edition, Paris, 1921. G Pachon : Journ. Méd. Français, September, 1919, No. 9. 'Matas : Joum. Amer. Med. Assoc., October; 1914.

\section{THE TREATMENT OF BURNS. BY}

D. MACKENZIE, M.B., Ch.B.Glasg., SOUTHERN GENERAL HOSPITAL, GOVAN.

ThIs note is the outcome of fourtcen months' experience as house-surgeon in burns wards. There every known method of dealing with the primary shock and in the aseptic and antiseptic treatment of the burns was tried.

During the last five rears $I$ have used as a routine Wright's hypertonic saline $(\mathrm{NaCl})$, with its recognized valuable results ${ }^{1}$; this in association with more active measures is the keynote of the method.

The line of treatment advocated is active surgical intervention, and consists of the immediate removal of all dead tissues under a general anaesthetic-preferably ether. The appreciation of what may be termed the demarcation line is soon acquired. My approach towards this appreciation was the removal of the dead tissue in fourth and fifth degree burns on the seventh day, at which time natural separation is appreciable, and thereafter proceeding in subsequent cases to earlier and eventually earliest removal. The degree of appreciation is not important, provided the error, if any, is on the side of free removal. The aim is the formation of a surgical field, and free removal, both at the skin and deep margin, is indicated. The presence of dead tissues results in toxaemia from the absorption of the products of autolysis, and usually a degree of septicaemia at the sloughing stage. To avoid this is the chief purpose; complete removal leaves a surgical field with the subsequent healthy granulation tissue of aseptic surgery.

The instruments used in the removal of dead tissue are razors, amputation knives, Volkmann spoons, heavy curettes, different types of scissors, toothed dissecting forceps, haemostatic forceps, etc. Where bone is involved the appropriate instruments are added. The solution employed is hypertonic $(\mathrm{NaCl})$. When demarcation has been exact there has been no danger of haemorrhage from oozing with applications of 5 per cent. hypertonic saline, or, where oozing is extensive, 2 to 3 per cent. In no case has there been haemorrhage. The gauze is wrung out of the hot saline and applied in close contact to the raw surface, layer on layer, and covered with wool. Jaconet is used as a covering where modification of the hypertonicity and the nature of the field might result in a painful adherent dressing. The gauze is removed by warm saline, irrigation, as distinct from soaking, being employed. At a liter stage in the repair, the stage where physiological saline is replacing hypertonic, "V" flap perforated silk is interposed to guard the granulations if required. The question of dressing daily, or twice daily, is particular to the case. Within a few days parts of the field are in most cases ready for pinch-grafts, provision for which should be made at the operation. When dealing with the skin margin, shelving of the margin is adopted, but at different parts small portions of the skin are left jutting towards the raw area, and these portions, when required, are readily removed by scissors curved on the flat. General pinch-grafting is governed by absolute freedom from dead tissue or sepsis and by the degree of granulation desired to replace loss of tissue. Dead tissue which may have bee! missed at operation should be dealt with by sharp scalpel or razor; for smaller portions the virtue of hypertonic saline need not be enlarged upon. A bland ointment is used to protect the rapidly germinating epithelium, otherwise physiological or hypertonic solutions of $\mathrm{NaCl}$ are employed throughout.

The question of how early the operation should be performed has to be viewed in relation to the degree of primary shock and the degree of difficulty which may he met with in estimating the line of demarcation at the particular site of the burn. Undue delay, on the other hand, must be guarded against on the following grounds. The active measures taken in combating the shock-the electric cage, pituitrin, camphor, ether, brandy, etc.; intravenous saline, rectal injections of saline, ghucose, essential oils, etc.; analgesics such as morphine, nepenthe, etc.; the various types of soothing applications, aluminium acetate, picric acid, protective wax preparations, etc.were in part nullified by the rapid absorption of the autolrtic products, this absorption from its toxaemia sustaining the shock. ${ }^{1}$ There is also the possibility that the autolytic processes in burns modify locally the natural efforts of repair, with a resultant change in the characteristics of the fibroblastic tissue. The ground for such a belief is the modification of the scar tissue, so frequently met with is burns, ranging as it does from hypertrophic scar tissue, keloidal to keloid, which, although regarded as an individual idiosyncrasy, is nevertheless most common in burns. It must be remembered too that equally severe shock is met with in other circumstances where immediate operation is indicated. There is also the stimulating effect of ether administration, and during this intravenous saline and other shock-combating treatment may be carried out. Post-operative treatment is attended to as in other surgical cases. Lastly, there is the psychological effect on the paticnt when the nausea of scorched flesh is replaced hy the sense of comfort from the soothing aseptic dressings, painlessly applied. The necessity to operate at a latel stage, when the patient is exhausted from toxaemia, if not by septicaemia, is avoided. The convalescence, characterized by asepsis and a rapid rate of healing, is considerably shortened and is free from discomfort.

The flexible type of scar tissue resulting from this procedure, with its potentiality for plastic considerations and minimum of contractures, lessens disfigurement. The nature also of the repair process prevents the former bugbear of burns repair. This was the terminal patch usually found at the summit or centre of the field. It was due to the inequality of repair rate at the deep and superficial parts of the scar, the contraction of the deep tissue interfering with the blood supply of the patch. The result was that this area might resist all methods of healing, including grafting, and take on a malignant character. Such a malignant ulcer is not infrequently seen on an old burn scar when it has broken down from stress or trauma. Similarly the treatment lessens the possibility of hypertrophic scar tissue. The absence of keloidal or keloid tissue in the cases dealt with must at present be regarded on the score of the patients' freedom from such idiosyncrasy. The 